
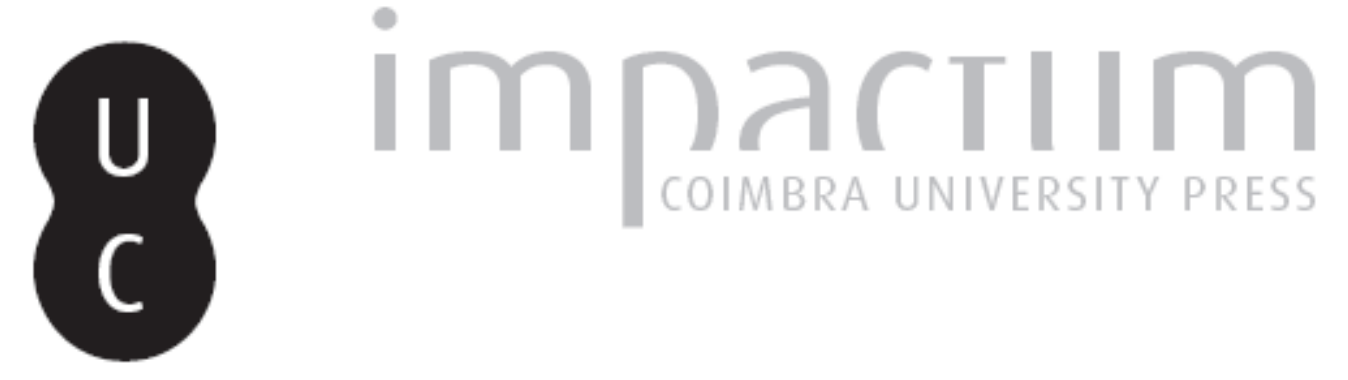

\title{
Stuff we love: afeto, presença e materialidade no design de livros
}

Autor(es): $\quad$ Andrioli, Larissa

Publicado por: Centro de Literatura Portuguesa

URL persistente:

URI:http://hdl.handle.net/10316.2/34685

DOI:

DOI:http://dx.doi.org/10.14195/2182-8830_2-1_6

Accessed : $\quad$ 26-Apr-2023 13:42:07

A navegação consulta e descarregamento dos títulos inseridos nas Bibliotecas Digitais UC Digitalis, UC Pombalina e UC Impactum, pressupõem a aceitação plena e sem reservas dos Termos e Condições de Uso destas Bibliotecas Digitais, disponíveis em https://digitalis.uc.pt/pt-pt/termos.

Conforme exposto nos referidos Termos e Condições de Uso, o descarregamento de títulos de acesso restrito requer uma licença válida de autorização devendo o utilizador aceder ao(s) documento(s) a partir de um endereço de IP da instituição detentora da supramencionada licença.

Ao utilizador é apenas permitido o descarregamento para uso pessoal, pelo que o emprego do(s) título(s) descarregado(s) para outro fim, designadamente comercial, carece de autorização do respetivo autor ou editor da obra.

Na medida em que todas as obras da UC Digitalis se encontram protegidas pelo Código do Direito de Autor e Direitos Conexos e demais legislação aplicável, toda a cópia, parcial ou total, deste documento, nos casos em que é legalmente admitida, deverá conter ou fazer-se acompanhar por este aviso.

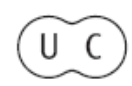




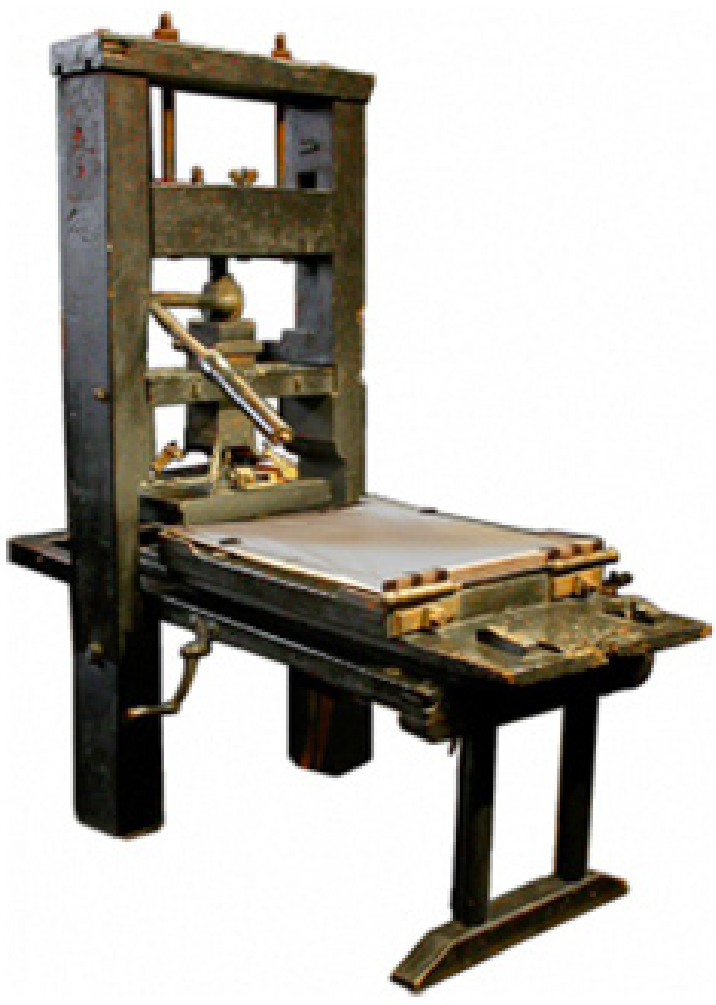

Vol. 2.1 (2014)

ISSN 2182-8830

'Livro e Materialidade'

Abel Barros Baptista (org.) 


\title{
Stuff we love: Afeto, Presença e Materialidade no Design de Livros LARISSA ANDRIOLI \\ Pontifícia Universidade Católica do Rio de Janeiro
}

\begin{abstract}
Resumo
O presente artigo pretende discutir a materialidade do livro através do design gráfico. Parte de duas diferentes possibilidades de observação do objeto: o design emocional de Donald Norman (complementado pela teoria dos afetos de António Damásio) e a produção de presença de Hans Ulrich Gumbrecht. Para entender como as duas se relacionam entre si e como se podem aplicar ao livro, uma das seções do artigo centra-se numa descrição háptica de três obras. Contrastando um livro tradicional com dois livros cujo design explora a sua materialidade táctil, este artigo se propõe a entender de que forma a configuração física do livro influencia a nossa percepção da arte através da mobilização de afetos. Palavras-chave: Produção de Presença; Design Emocional; Estudos de Afeto; Design Gráfico; Materialidade do Livro.
\end{abstract}

\section{Abstract}

The present article aims to discuss the materiality of the book through graphic design. It begins with two different ways of looking at the object: the emotional design approach by Donald Norman (complemented by Antonio Damasio's affects theory) and the production of presence approach by Hans Ulrich Gumbrecht. To understand how those theories can be related and how they can apply to books, one of the sections is dedicated to describing the haptic qualities of three books. By contrasting a traditional book with two books whose design explores their tactile materiality, this article tries to understand how the physical embodiment of the book influences our perception of art through affective interactions. Keywords: Production of Presence; Emotional Design; Affect Studies; Graphic Design; Materiality of the Book.

Interpretation is the revenge of the intellect upon art. Susan Sontag

$I$

$\mathbf{E}$ m seu ensaio "Uma cultura e a nova sensibilidade", de 1966, Susan Sontag afirma que "nós somos o que somos capazes de ver (ouvir, tocar, cheirar, sentir) inclusive mais forte e mais profundamente do que somos o conjunto das ideias que armazenamos em nossa cabeça” (300, tradução minha). A reflexão de Sontag parece mais adequada do que nunca quando observamos o mercado editorial hoje, que apresenta cada vez mais ofertas de edições que apostam em um melhor acabamento estético como diferencial. Esta melhoria aparece desde os recursos mais simples - a escolha adequada do material das folhas e do estilo tipográfico, o investimento em uma capa bem desenhada - até a criação dos projetos gráficos mais MATLIT 2.1 (2014): 119-134. ISSN 2182-8830

http://dx.doi.org/10.14195/2182-8830_2-1_6 
inovadores. Nesse cenário, surgem editoras que têm a questão gráfica como foco de seu trabalho e que parecem levar em conta a colocação de Sontag na hora de produzir seus livros.

Um dos maiores exemplos é a editora paulista Cosac Naify, reconhecida pela qualidade gráfica de seus produtos. Fundada em 1997 por Charles Cosac e Michael Naify, tinha, primeiramente, o intuito de publicar livros de arte e arquitetura de alto nível no Brasil. Este objetivo inicial é importante para entender por que, ao ingressar na publicação de prosa, a editora chamou tanto a atenção dos leitores. Ao se dedicar à publicação de livros de arte, a Cosac se habituou ao tratamento especial que deve ser dado aos atributos materiais desse tipo de livro. Assim, ao iniciar a publicação de livros de literatura e ciências humanas, destacou-se pela produção diferenciada que dispensava aos projetos gráficos de seus livros. Desde então, tem surpreendido a cada nova coleção pela inovação gráfica, seja somente nas capas ou também no projeto do miolo. Uma coleção específica se destaca no catálogo da editora: a Coleção Particular. Formada por clássicos da literatura ocidental, traz apenas narrativas curtas trabalhadas por projetos gráficos que fazem parte da experiência de leitura, interferindo na experimentação do texto. A coleção conta com sete títulos, e, em todos, as configurações visuais e materiais do livro estão integradas ao desenrolar da trama ou ao estilo da narrativa.

Outra editora que tem como diferencial a questão visual é a londrina Visual Editions. Fundada em 2010 por Anna Gerber, professora de design gráfico, e Britt Iversen, designer, com o propósito de unir literatura e design, tem como lema produzir "great looking stories". Seu investimento é no que chamam de visual writing, ou escrita visual, que definem como o ato de apresentar elementos visuais que acrescentem à história contada tanto quanto as palavras que ali estão, que não tenham somente finalidade decorativa, mas sejam uma chave para a leitura, de forma que, sem eles, a história seja algo completamente diferente. Há, assim, um entrelaçamento tão grande de escrita e visualidade que se torna impossível separar os dois elementos sem que haja grandes perdas para o livro. Desde sua fundação, a Visual Editions lançou cinco títulos, dentre reedições e inéditos, e todo o catálogo é composto por livros que buscam, de alguma forma, estabelecer um contato físico diferenciado com o leitor.

Tentarei aqui estabelecer algumas relações entre estas editoras, seus projetos editoriais e a produção de afetos. Para isso, farei uma visita ao trabalho do neurocientista António Damásio, que discorre sobre a questão das emoções e dos sentimentos; conversarei também com o conceito de design emocional criado por Donald Norman; buscarei ainda a pesquisa de Hans Ulrich Gumbrecht acerca da produção de presença; e, por fim, dialogarei com os escritos de Karin Littau sobre o papel dos afetos na literatura. Creio ser possível estabelecer uma relação entre os pensamentos citados e a experiência que tenho com alguns livros que possuem um design diferenciado da maioria. 
Em seu livro Design Emocional - Por que amamos (ou odiamos) os objetos do dia-a-dia (2008), Donald Norman investiga qual o papel do design na produção de gosto ou rejeição a um objeto por parte do usuário. A partir de uma série de exemplos de objetos de sua coleção pessoal, ele ilustra seus argumentos e define algumas categorias dentro do design. Ele diz, por exemplo, que há um forte componente emocional na maneira como os produtos são concebidos e postos em uso, e que esse lado emocional pode até mesmo ser mais decisivo para o sucesso de um produto que seus elementos práticos (24). Isso acontece também nos exemplos de livros que descreverei aqui.

Norman define o afeto como a parte do comportamento humano que é subconsciente, abaixo da percepção consciente. Trata-se do sistema de julgamentos que nos ajuda a determinar as coisas no ambiente que são perigosas ou seguras, boas ou más. Já emoção seria a experiência consciente do afeto, atribuindo a ele uma causa e identificando seu objeto. A cognição e o afeto influenciam um ao outro: algumas emoções e sensações são motivadas e impulsionadas pela cognição, enquanto o afeto geralmente se choca com a cognição (31). As emoções alteram a forma como o sistema cognitivo funciona, alterando a maneira como a mente humana soluciona problemas.

Outro aspecto interessante do estudo de Norman é a divisão que ele faz entre os três níveis de processamento do cérebro: a camada automática e préprogramada, chamada visceral; a parte que contém os processos cerebrais que controlam o comportamento cotidiano, denominada comportamental; e a parte contemplativa, ou reflexiva. Cada nível desempenha um papel diferente no funcionamento do ser humano como um todo. O nível visceral é rápido, julga o que é bom ou ruim, seguro ou perigoso, envia sinais para os músculos e alerta o resto do cérebro. O nível comportamental é onde está localizada a maior parte do comportamento humano. Suas ações são aperfeiçoadas ou inibidas pelo nível reflexivo e ele pode também aperfeiçoar ou inibir os reflexos do nível visceral. O nível reflexivo não tem acesso direto às informações sensoriais nem ao controle de comportamento; apenas observa, reflete sobre o nível comportamental e tenta influenciá-lo (41-42). Para Norman, a leitura de uma obra literária se encontra no estágio reflexivo. Mas tudo que fazemos tem, ao mesmo tempo, um componente cognitivo e um afetivo, pois os três níveis entrelaçam-se na prática. Observar um quadro de Matisse está no nível reflexivo, mas a reação visceral do nosso corpo às cores que vemos modifica a percepção que temos do quadro.

Cada nível de processamento, diz Norman, exige um tipo específico de design. O nível visceral é anterior ao pensamento, é onde a aparência importa e as primeiras impressões são formadas. Esse nível diz respeito ao impacto inicial do produto, à sua aparência, toque e sensação (56). Já o nível comportamental trata do uso e da experiência que temos com um produto 
em três aspectos: função, desempenho e usabilidade. A função abarca as atividades que o produto suporta; se as funções são inadequadas ou não têm interesse, o produto não tem valor. $\mathrm{O}$ desempenho está relacionado à execução da função; se ele não tem bom desempenho, não é um bom produto. A usabilidade descreve a facilidade com que o usuário do produto pode compreender como ele funciona e fazê-lo funcionar. Um produto que gera confusão ou frustração no usuário resulta em emoções negativas. Mas, caso o usuário seja recompensado e se divirta usando o produto, o resultado é a geração de afeto positivo (57). No nível reflexivo residem a consciência e os níveis mais altos de sentimentos, emoções e cognição. Somente nele o impacto pleno do pensamento e da emoção é experimentado (58). Sobre a importância da dimensão física dos objetos, Norman diz:

Os objetos físicos têm peso, textura e superfície. O termo de design para isso é "tangibilidade". Um número grande demais de criações de alta tecnologia evoluiu de controles e produtos físicos reais e concretos para outros em telas de computador que passaram a ser operados por um toque na tela ou pelo manejo do mouse. Todo o prazer de manusear um objeto físico desapareceu e, com ele, um sentido de controle. A sensação física é importante. Afinal, somos criaturas biológicas, com corpos físicos, braços e pernas. Uma parte enorme do cérebro é ocupada pelos sistemas sensoriais [...]. (102)

Os níveis de design (e de processamento) devem, portanto, ser trabalhados de forma integralizada para a construção de um produto com design equilibrado em seus impactos, funções e reflexões consequentes.

Em uma perspectiva similar a de Norman, encontramos os estudos de António Damásio sobre as emoções e sentimentos. Em seu livro Em busca de Espinosa: prazer e dor na ciência dos sentimentos (2004), Damásio oferece dados interessantes para os estudos na área emocional. Para discorrer sobre e entender os afetos, ele os separa em um primeiro componente, as emoções, e nos sentimentos, o segundo componente. Para Damásio, os sentimentos "são a expressão do florescimento ou do sofrimento humano [...] podem ser, e geralmente são, revelações do estado da vida dentro do organismo" (15). Damásio define o sentimento como a parte privada do processo emocional e emoção como a parte pública. Relacionando com o que já foi falado sobre Norman, pode-se pensar na emoção como parte do nível visceral - a expressão de susto ou de prazer, por exemplo - enquanto o sentimento é o processamento reflexivo dessa emoção - pensar sobre por que você se assustou ou o que gerou seu prazer, direcionar essas emoções. "As emoções ocorrem no teatro do corpo. Os sentimentos ocorrem no teatro da mente" (35) - ou seja, os sentimentos são invisíveis para o público, enquanto as emoções ocorrem na voz, no rosto ou em comportamentos específicos, que podem ser públicos. 
As emoções são, para Damásio, um meio natural através do qual podemos avaliar o ambiente que nos cerca e reagir de forma adaptativa. Os objetos que nos causam emoções podem por vezes ser avaliados, ou seja, observados no contexto em que estão e relacionados a esse contexto, a outros objetos ou ao passado. A partir dessa avaliação, afirma Damásio, podemos modular nossa resposta emocional. Mas nem sempre as emoções ocorrem de forma a tornar possível a análise do objeto que as causa ou da situação em que esse objeto aparece. Algumas das emoções que sentimos estão relacionadas a experiências individuais que associamos a diversas outras situações ao longo da vida. Surge assim o gosto ou aversão que nutrimos por alguns objetos, e Damásio ressalta que é difícil imaginar objetos emocionalmente neutros, ou seja, que não tenham nenhuma emoção associada a eles por alguém. E esses objetos de nossas experiências diárias têm a capacidade de desencadear reações homeostáticas que são acompanhadas necessariamente por estados do corpo cuja percepção é o sentimento, ao que se segue a percepção de pensamentos com certos temas e de um determinado modo de pensar. Tudo isso remete à causa (o objeto) que lhe deu origem (90-92). Para Damásio, a essência dos sentimentos de emoções consiste em pensamentos sobre o corpo surpreendido no ato de reagir a determinados objetos e situações. Sem a dimensão corporal, não é possível falar em sentimentos. Como Norman destaca, boa parte do cérebro é ocupada por sistemas sensoriais, de forma que o corpo está continuamente sendo mapeado e, a partir disso, as imagens mentais são construídas - por isso, a dimensão corporal é o substrato imediato dos sentimentos. Assim, "O conteúdo essencial dos sentimentos é um estado corporal mapeado num sistema de regiões cerebrais a partir do qual uma certa imagem mental do corpo pode emergir" (95). O sentimento de uma emoção surge quando o corpo é perturbado pelo processo emocional.

\section{III}

Em 2004, Hans Ulrich Gumbrecht publicou Produção de Presença - o que o sentido não consegue transmitir (edição brasileira, 2010), livro no qual apresenta um conceito fundamental para os estudos contemporâneos de literatura, que é a noção de presença. A partir de uma releitura de Heidegger, ele desenvolve sua argumentação, baseada em seus estudos das materialidades da comunicação, e tenta discutir a formação hermenêutica dos estudos de literatura.

O primeiro e principal ponto a ser discutido é a questão da experiência estética como um espaço para a oscilação entre presença e sentido. Isso ocorre, por vezes, como uma interferência, de modo que, em alguns momentos, o sentido se destaca, enquanto que, em outros, a presença tem um efeito maior. Gumbrecht ressalta diversas vezes que seu estudo não é 
uma tentativa de apagar as leituras dos efeitos de sentido, e é importante dizer que este trabalho também pretende apenas mostrar uma nova perspectiva nos estudos de literatura - perspectiva esta que tenciona ressaltar a presença, e não ignorar o sentido. Define-se, então, a materialidade como "fenômenos e condições que contribuem para a produção de sentido, sem serem, eles mesmos, sentido" (Gumbrecht, 2010: 28). Portanto, para falar de presença é essencial que pensemos em algo físico; a presença de que tratamos é uma referência espacial, algo tangível. A produção de presença designa, enfim, os processos que iniciam ou intensificam o impacto de objetos presentes sobre o corpo humano, já que "produção", no conceito gumbrechtiano, retoma seu sentido do latim, que é o ato de trazer para diante um objeto no espaço.

O conceito de Gumbrecht firma, portanto, o compromisso de "lutar contra a tendência da cultura contemporânea de abandonar, e até esquecer, a possibilidade de uma relação com o mundo fundada na presença” (15). A produção da presença fala, por fim, de uma tangibilidade da comunicação, um movimento permanente no espaço que oscila entre maior e menor proximidade, maior e menor intensidade. As formas literárias se encontram sempre num estado de tensão, em permanente oscilação entre dimensão de sentido e dimensão de presença, de materialidade.

É possível descrever a relação do sujeito com o mundo através da interseção de dois eixos: o primeiro, horizontal, opõe o sujeito, observador, e o mundo, conjunto material; o segundo, vertical, se trata da interpretação que o sujeito faz do mundo, como ele penetra na superfície do mundo para extrair dele conhecimento. Esse paradigma, no caminho da cultura ocidental moderna, privilegia a dimensão temporal em detrimento da espacial. Assim, a predominância do cogito resulta numa saturação cada vez maior da interpretação do mundo, enquanto que a produção de uma presença "real" é deixada de lado (56). O paradigma sujeito/objeto é que exclui e impede que tenhamos o mundo como referência, de forma que, para que esta referência seja retomada, devemos tentar retomar o contato com as coisas, seja fora ou em outra versão desse paradigma. Assim, podemos evitar a interpretação, o discurso proposicional sobre o texto, atendo-nos à presença, à aparência textual - o que, aqui, significa tudo aquilo que se mostra aos sentidos do ser humano.

Gumbrecht distingue dois tipos de cultura: a cultura do sentido e a cultura da presença - a primeira tem a mente como principal referência do homem, enquanto o corpo ocupa esse lugar na segunda. $\mathrm{Na}$ cultura da presença, o homem e sua materialidade encontram-se como parte de algo maior, e não à parte do mundo, como acontece na cultura de sentido. Um mundo de presença está fundado na noção de eventness, que não se trata da inovação ou da surpresa. O autor associa esse conceito ao início de uma apresentação de orquestra: apesar de sabermos o horário para o qual o início está agendado, somos atingidos pelos primeiros acordes, que produzem a 
sensação de eventness. A experiência estética da presença está ligada, principalmente, à intensidade. Os momentos de intensidade da presença nunca são garantidos, não podemos contar com eles, e, mesmo assim, sempre que surgem oferecem a nós algo que nosso mundo cotidiano, calcado na metafísica e na proposição de sentidos, nos nega. Por isso os objetos de experiência estética nos fascinam tanto, por contrastarem com um mundo saturado de sentidos que não nos dá o que precisamos. Por vivermos nesse mundo centrado na consciência e na produção de sentidos, precisamos ter experiências tangíveis, que se aproximem de nossa pele.

Ao encarar um fenômeno de presença, entretanto, já nos deparamos com ele envolvido por uma nuvem de sentidos, pois estamos no meio de uma cultura do sentido. Dessa forma, os objetos de experiência estética se apoiam numa oscilação entre os efeitos de presença e os efeitos de sentido. A força da presença e a força do sentido, entretanto, não agem como estabilizadores do objeto estético - pelo contrário: é justamente essa tensão entre as duas potências que o desestabiliza.

$\mathrm{Na}$ leitura de um texto escrito, a dimensão de sentido normalmente se impõe, mas sempre há a possibilidade de que a presença se mostre na tipografia, no ritmo da linguagem ou até mesmo na materialidade do papel: na textura ou no cheiro. A defesa de Gumbrecht, e também deste texto, é de que em certo momento, apesar da possível predominância dos efeitos de sentido, possamos parar de nos perguntar o que algo significa - e permitirmo-nos simplesmente experienciar o objeto de experiência estética como uma possibilidade de sentir a presença deles.

\section{IV}

Para entender de que forma o que falei até agora sobre como os afetos e a presença se integram ao design de livros, é preciso se entregar aos próximos parágrafos de leitura. Tentarei, ainda que precariamente, descrever dois objetos que considero potentes para entender a relação que as sensações físicas causadas pelo manuseio de um livro projetado de forma diferenciada podem estabelecer com a criação de afetos durante a leitura. Em oposição a estes dois objetos, descreverei primeiro um objeto cujo design é considerado tradicional, sem desvios do que normalmente se espera de um livro.

Primeiramente, portanto, vou me dedicar a este livro que chamo, aqui, de tradicional. Dentre os diversos livros empilhados ao meu redor, poderia escolher praticamente qualquer um de editoras como Record ou Companhia das Letras. Escolhi para descrever um dos livros que integra a parte teórica deste texto: Em busca de Espinosa, de António Damásio. Publicado pela Companhia das Letras em 2004, o livro possui o formato padrão de $14 \mathrm{~cm}$ de largura por $21 \mathrm{~cm}$ de altura, que é o mais utilizado atualmente. A capa foi elaborada por Raul Loureiro sobre obra sem título $(1968,1971)$ de Cy 
Twombly; a tela é composta por tons de azul acinzentado e traços brancos e se trata claramente de uma capa de destaque em livrarias; sua simplicidade e abstracionismo chamam atenção e despertam a curiosidade caso o livro seja visto de longe, o que faz com que o possível-futuro-leitor se sinta compelido a se aproximar e ver do que se trata.

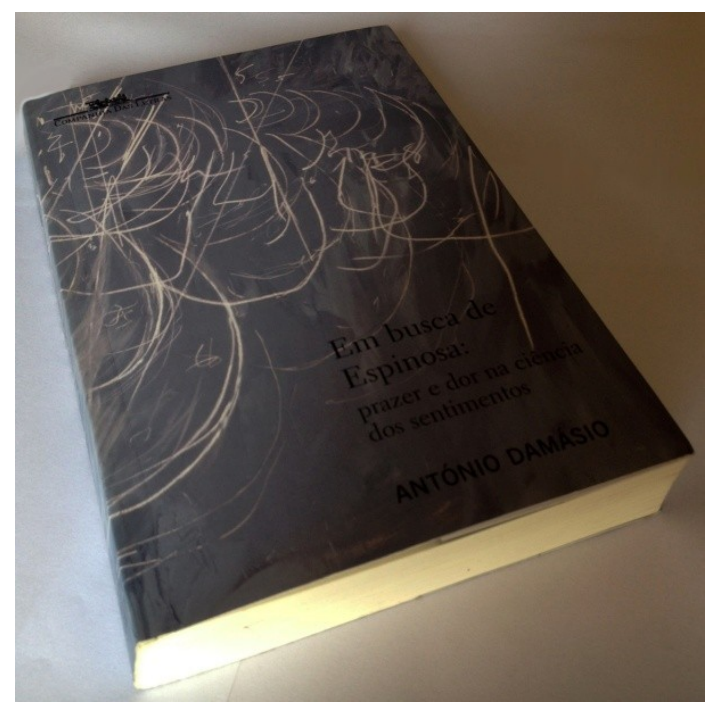

Figura 1.

Ao se aproximar do livro e tocá-lo, o que se vê é um livro de excelente acabamento gráfico e técnico. A capa, que já havia sido vista de longe, agora pode ser apreciada em detalhes: o detalhe da tela de Cy Twombly foi sobreposto com uma tipografia serifada simples no canto inferior direito apresentando o título do livro e, logo abaixo, o nome do autor aparece em caixa alta em tipografia sem serifa. No canto superior direito, encontra-se o logo da Companhia das Letras. Tudo isso foi impresso sobre cartão supremo $250 \mathrm{~g} / \mathrm{m}^{2}$, o que confere ao livro um corpo firme. Na quarta capa, na metade inferior, somos apresentados a um pequeno resumo do conteúdo, seguido de dois trechos de críticas sobre o livro. Extensões da capa e quarta capa, mas já na parte interna, as orelhas - com $7 \mathrm{~cm}$ cada - apresentam as informações tradicionais: na primeira, próxima à capa, somos introduzidos às questões nas quais o livro se aprofundará; na segunda, perto da quarta capa, vemos uma foto e uma pequena biografia do autor.

Por fim, chegamos ao miolo do livro, que é composto por onze cadernos de texto ao todo, costurados individualmente com linha branca e colados juntos no cartão que forma capa, quarta capa, orelhas e lombada. O papel utilizado para o miolo é o pólen soft, que possui um toque agradável, além de coloração creme, o que propicia uma leitura confortável. Essa é, na verdade, a chave das configurações gráficas deste livro. Isso porque, ao observar o 
texto, é possível notar que a tipografia da capa se repete no corpo, e ela é feita especialmente para a leitura, pois em nenhum momento apresenta ambiguidades nas letras, é sempre clara quanto aos caracteres. Além disso, o espaçamento utilizado pelos responsáveis pela diagramação (a empresa Spress) é ideal para a leitura, pois as linhas de texto apresentam a distância necessária entre si para que não haja confusão ou cansaço da vista.

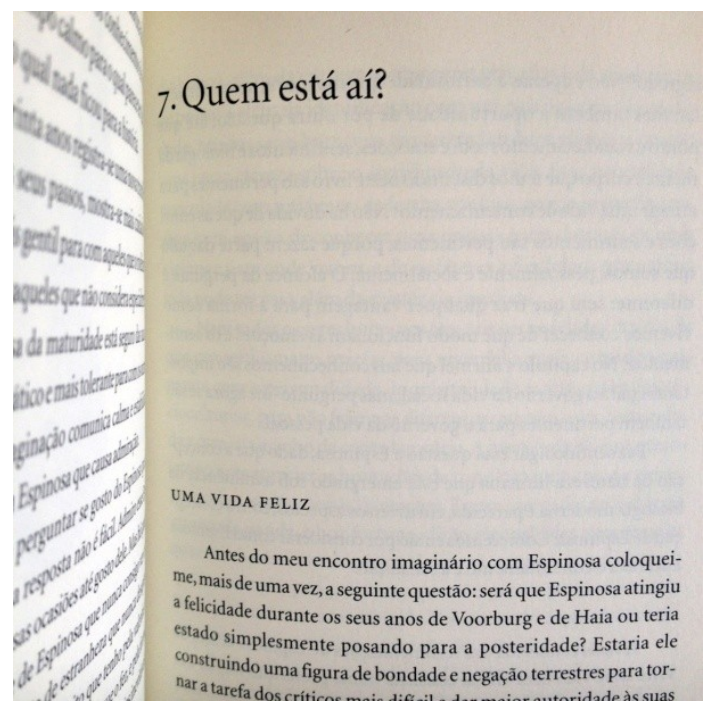

Figura 2.

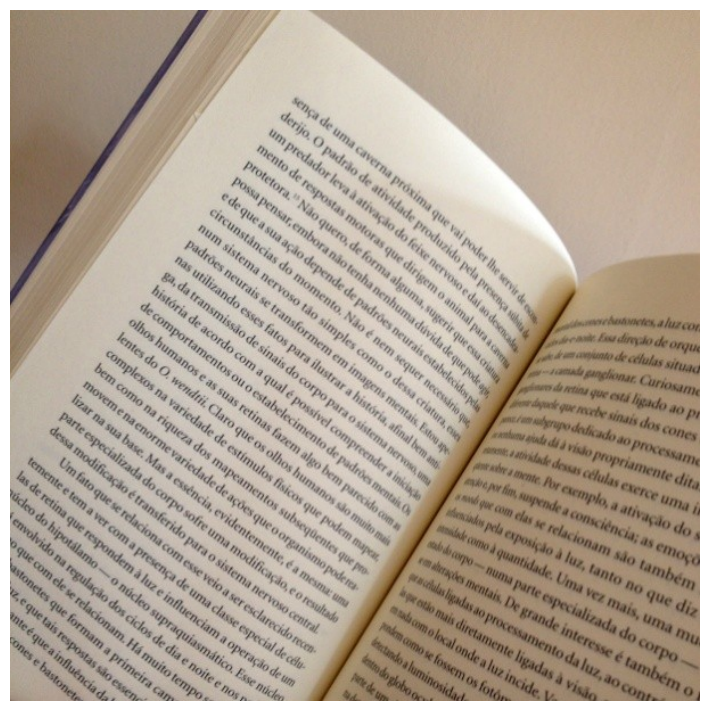

Figura 3. 
O livro descrito aqui, portanto, é feito na medida certa para desaparecer em nossas mãos assim que começamos a lê-lo: a textura das páginas não incomoda nossos dedos, o desenho da tipografia não nos confunde, a cor do papel, juntamente com o espaçamento adequado, não deixa que nossa vista se canse com a leitura. Trata-se, portanto, do investimento das tecnologias mais avançadas - de fabricação de papel, de diagramação, de criação de tipografias específicas para a leitura - na função de criar um livro que é tão bem feito que nós nem percebemos que o temos em mãos. O que importa nesse objeto é o que ele tem a dizer com as palavras.

Passemos agora aos dois objetos que pretendo opor a esta forma de produzir livros. O que tentarei mostrar é que a mesma tecnologia utilizada pela Companhia das Letras para apagar a materialidade do livro em nossas mãos pode ser utilizada com intenções opostas, ou seja, destacando essa materialidade.

O primeiro objeto que descreverei aqui é uma edição de Bartleby, o escrivão, de Herman Melville, lançada pela editora Cosac Naify em 2005. Trabalhando a partir de um clássico da literatura, é relativamente fácil construir edições que representem o espírito do livro, mas o que foi feito pela designer Elaine Ramos nesse caso foi além do que se espera de uma edição tradicional. Visto de longe, o livro não chama muito a atenção, pois não tem cores ou imagens fortes na capa. Pelo contrário, à medida que nos aproximamos, é possível notar que a capa verde parece desgastada, com as bordas desbotando para um tom ocre, como se fosse um livro antigo esquecido na estante. $\mathrm{O}$ resto visível num primeiro momento - os outros elementos da capa, a quarta capa - também sugere se tratar de um exemplar já utilizado e de longa data: a tipografia utilizada para o nome do autor tem alguns floreios e o título é grafado em tipos romanos vazados para simular alto-relevo, recursos comumente utilizados em capas clássicas e bem distantes do que se vê hoje em dia.

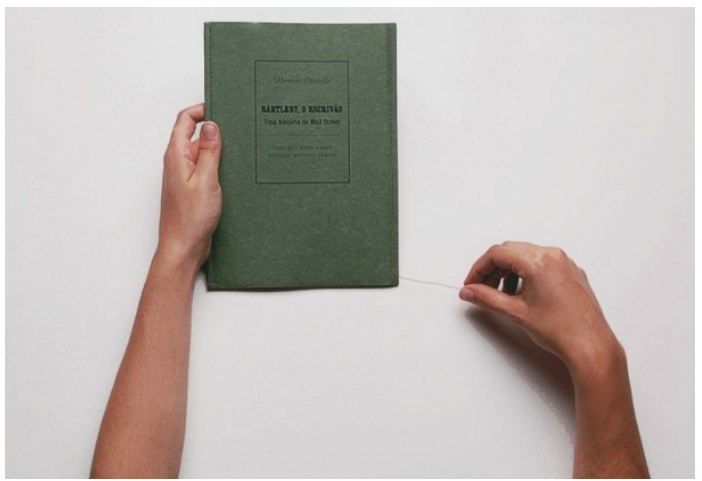

Figura 4. 
O objeto chama a atenção por dois motivos: primeiramente, apresenta tamanho diferente do padrão $14 \times 21$; é um pouco maior e tem as dimensões $16,9 \mathrm{~cm}$ de largura por $22,8 \mathrm{~cm}$ de altura. Passado o estranhamento do tamanho do livro em nossas mãos, surge um outro problema: no lado esquerdo, vemos uma linha que costura os cadernos de texto - e, ainda que não seja muito comum que essa linha esteja exposta na capa, ela está cumprindo sua função no exato lugar a que pertence. Mas, do lado oposto, há outra linha, costurando as beiradas da capa junto à quarta capa e impedindo que o livro seja aberto. Assim, somos apresentados a uma possibilidade de escolha: podemos escolher abrir o livro ou não. Entretanto, um livro que tem a aparência de antigo e está selado definitivamente tem potencial para despertar a atenção do leitor. Então, ele entra na encenação proposta pelo livro: a encenação da espera, do adiamento da leitura e do conhecimento do que está ali dentro daquele objeto tão bem guardado por tanto tempo. E quando finalmente termina o exercício de descosturar o livro e abre a capa de cartão verde rígido, encontra um muro. A primeira imagem que há nas páginas é um muro que toma toda a folha. Ao passar as páginas, entretanto, descobrimos que não se trata de uma imagem de abertura do livro, mas todas as páginas encontram-se cobertas pela mesma figura e não há qualquer texto à vista.

Até que, no meio do livro, surge um instrumento de plástico, parecido com um marcador de livros, com o logo da editora impressa. Um olhar mais atento descobre qual sua serventia: as páginas cobertas pelo muro são, na verdade, folhas duplas esperando que usemos o instrumento como faca de corte para abri-las e, enfim, revelar o texto. É só depois de refilar todas as páginas que o leitor pode finalmente ter acesso ao conto de Melville.

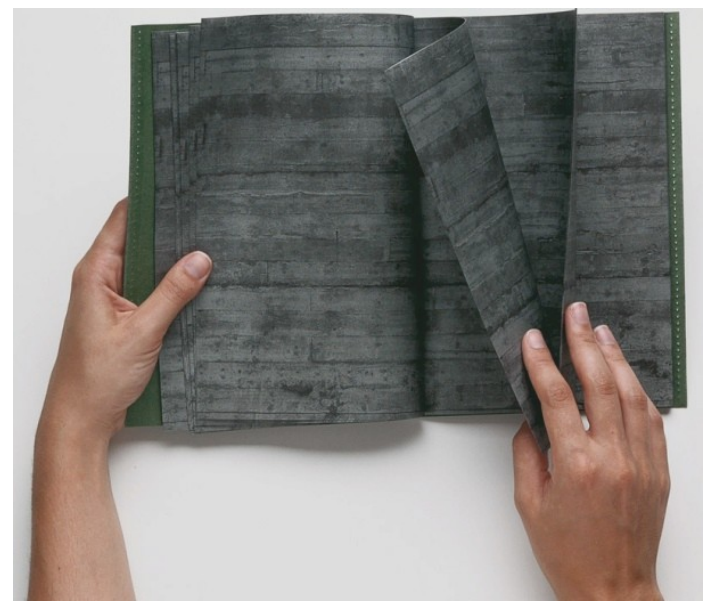

Figura 5. 


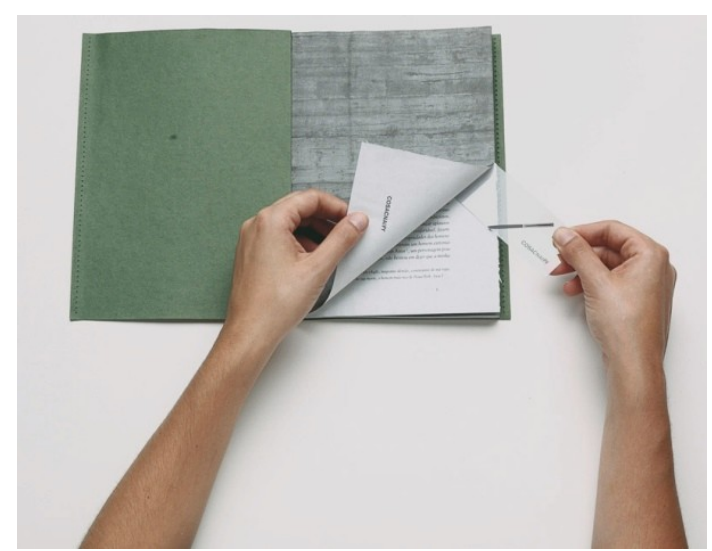

Figura 6.

O projeto criado por Elaine Ramos, portanto, obriga o leitor a fazer escolhas a todo momento: descosturar ou não, refilar ou não, em suma, ler ou não ler. Ao possibilitar que essas escolhas sejam feitas (ou não) pelo leitor, o design gráfico projeta no leitor o próprio Bartleby, que escolhe preferir não fazer o que lhe é pedido. Há também uma lógica de recompensa nesta edição: a cada escolha positiva que o leitor faz, ganha algo em troca, até que, por fim, ganha o prêmio final, que é o texto. Assim, o contato do leitor com o livro e a inserção daquele neste são maximizados pelo projeto gráfico do livro, que investe nas sensações.

Passemos agora ao segundo objeto. Trata-se de um exemplar de Tree of Codes, de Jonathan Safran Foer, publicado em 2010 pela Visual Editions. Ao contrário de Bartleby, sua capa, criada por Jon Gray, do estúdio gray318, possui elementos gráficos que chamam a atenção mesmo vista de longe: sobre base branca, foram impressas formas pretas, circulares e irregulares por toda a capa, remetendo a um padrão polka dot malfeito. Em alguns trechos, entretanto, essas "manchas" são apagadas e substituídas por letras, formando o nome do autor (em letras vermelhas) e o título do livro (em letras pretas). A tipografia, que lembra a família Times, tem a particularidade de estar alocada de forma irregular, de forma que, embora as letras estejam, em sua grande maioria, espaçadas com um grande intervalo entre si, alguns pares de letras aparecem próximos, como é o caso de "re" em "tree", "fr" em "safran", "er" em "foer" e "co" em "codes". Assim, o espaço entre as letras sugere que, entre cada uma delas, havia outra, que foi apagada, exceto nos casos mencionados, nos quais a proximidade entre as letras indica que, na configuração original do texto que se esconde na capa, elas já se encontravam juntas. 


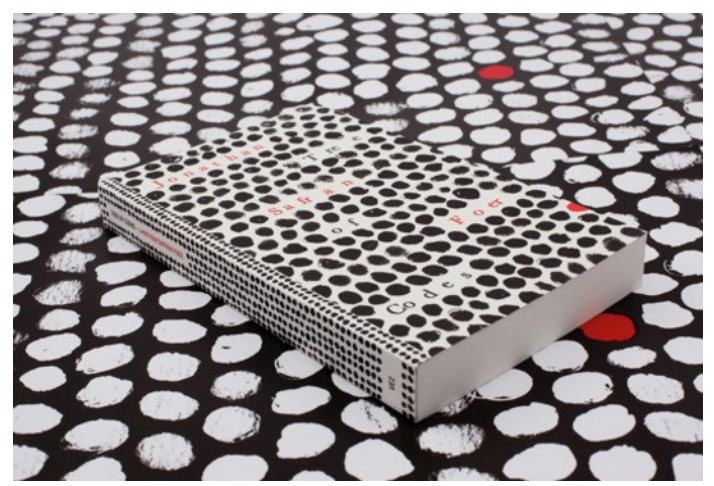

Figura 7.

$\mathrm{Na}$ quarta capa, abre-se um espaço em branco em meio às formas circulares para os trechos de críticas sobre o livro, que não poderiam ser mais animadores: "Revolutionary" (The New York Times) e "a true work of art" (The Times) são alguns dos comentários. Ao abrir o livro, as formas circulares se repetem na parte interna da capa, e uma linha delas é projetada na primeira página interna. Esse padrão de linhas de formas circulares se repete, aparecendo em todas as páginas até a dedicatória. É quando viramos esta página que descobrimos a que se referia Olafur Eliasson na quarta capa ao dizer que Foer "welds narrative, materiality, and our reading experience into a book that remembers it actually has a body". A primeira página, que teoricamente abrigaria o início da narrativa, está vazia. E por "vazia” quero dizer não só "em branco", mas também "vazada". Como se o texto que estava ali antes tivesse sido recortado, deixando uma página com buracos onde antes havia uma página com texto. Através desses buracos, podemos ver que há palavras nas outras páginas, mas todas elas estão também recortadas, como se um texto tivesse sido removido dali, deixando algumas palavras para que se formasse um novo texto.

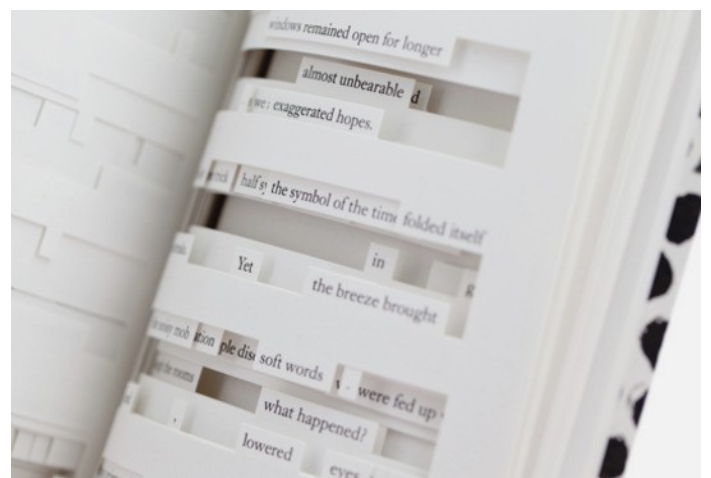

Figura 8. 


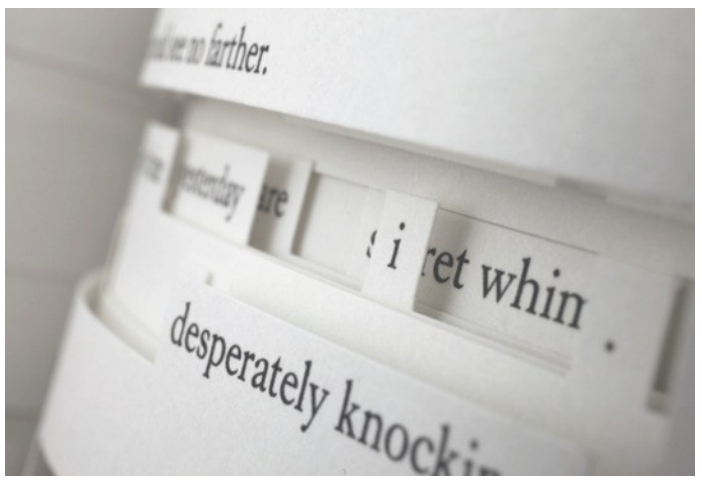

Figura 9.

$\mathrm{Na}$ verdade, é exatamente o que aconteceu. O próprio Foer explica no final do livro: "[f]or years I had wanted to create a die-cut book by erasure, a book whose meaning was exhumed from another book". E depois de tentar com diversos objetos-base diferentes, desde uma enciclopédia até um catálogo telefônico, ele se decidiu por The Street of Crocodiles (1934), de Bruno Schulz. Assim, apagou desde pontos até parágrafos inteiros, deixando somente o que interessava para formar a nova narrativa. Mas o corpo do livro anterior continuou presente, como destacou Eliasson, marcado pelas cicatrizes feitas por Foer. Cicatrizes que contam uma história diferente e modificam o olhar do leitor sobre o objeto que tem nas mãos. A materialização do corpo do livro é algo que a Visual Editions deseja realizar em suas publicações, porque, nas palavras das próprias fundadoras da editora, "the more we live on screen, the more we need stuff in our lives that we love" (Kurland). E esse afeto que elas desejam criar através das suas edições é gerado por livros que fisicamente se propõem a afetar as pessoas pelo toque da pele.

O projeto gráfico interno de Tree of Codes foi criado pelo estúdio Sara De Bondt e recusado por todas as gráficas que a VE procurou, até que a die Keure, na Bélgica, aceitou o desafio de produzir um livro com uma lâmina de corte diferente para cada página. A finalização do livro foi feita à mão pela Beschutte Werkplaats. A produção de um livro como Tree of Codes investe na mobilização dos sentidos do leitor, provocando-os.

Os dois projetos aqui mostrados fazem parte de dois projetos maiores, pertencentes às duas editoras, que propõem uma mudança na relação entre livro e leitor. Esta mudança baseia-se na transformação da experiência de leitura que busca somente um sentido em uma experiência que busque a sensação. Assim, ao produzir novas relações baseadas no retorno ao toque (como menciona Gumbrecht), esses livros acabam por produzir uma troca de afetos. 
Mas qual é, afinal, o papel da produção de afetos na literatura? Para que serve mobilizar os afetos do leitor e produzir sensações, seja através das palavras, seja através do design criado para abrigar as palavras, como é o caso dos objetos aqui mostrados? Para pensar sobre isso, chamo para o diálogo Karin Littau, que defende que respondemos à literatura de formas diferentes no que concerne às reações e ações que temos quando a lemos - e, ainda que não tenha havido muitas dúvidas entre os críticos de que o papel da literatura era ensinar, dar prazer e comover, pouco se fala sobre esta terceira função. Convocando Alfred Nuzman, Littau ressalta que "la reacción ante un poema no es en absoluto una respuesta a sus cualidades intelectuales, o a su significado, sino una respuesta a las sensaciones que puede evocar la poesía" (137). A tradição crítica, entretanto, advoga por uma literatura que tenha somente apelo intelectual, apagando o último dos três objetivos retóricos, que atribui valor à literatura também por ser capaz de comover o público. $\mathrm{O}$ consumo de literatura e sua recepção, entretanto, não dizem respeito somente ao conhecimento, à sabedoria e à intelectualidade - têm também relação com os afetos, os sentimentos e as sensações. Mesmo as correntes críticas que se ocupam do leitor só manifestam interesse por suas atividades mentais. Esquece-se que tanto o crítico especializado quanto o leitor corriqueiro possuem um corpo e que a literatura afeta também esse corpo.

Ao obrigar o leitor de Bartleby, o escrivão a sair da sua zona de conforto, o projeto gráfico desta edição não só investe em uma experiência interativa de leitura, mas principalmente em uma experiência sensitiva. É permitido ao leitor escolher entre diversos caminhos durante o ritual de início da leitura. E todos estes caminhos são palpáveis, encontram-se literalmente nas mãos do leitor, que pode optar por descosturar ou não o livro, refilar ou não as páginas - experiências que afetam o leitor e a leitura.

Já em Tree of Codes a proposta é jogar não com a escolha do leitor, mas do autor: a seleção feita por Safran Foer entre as frases originais para formar o novo livro está explícita em cada página, e a mobilização de afetos se dá não pelas possibilidades que o leitor tem diante de si, mas pela tactilidade do objeto que ele segura. Cada página é uma reafirmação de que livro é matéria e a matéria que foi modificada (reduzida, no caso) sempre deixará rastros. O leitor é, aqui, afetado pelas cicatrizes (quase literais) do processo de composição da obra.

O que projetos gráficos como os apresentados aqui propõem é a diluição da fronteira criada entre as funções corporais e as atividades intelectuais. A partir do contato com eles, torna-se possível experimentar sensações que se unem à leitura tradicional, criando novas formas de experiência da literatura, baseadas não somente na intelectualidade convencional, mas na criação de uma nova possibilidade, através da experiência sensitiva. Não mais se trata de uma arte separada da visualidade ou do toque - esses objetos promovem a confluência da tangibilidade com a intelectualidade em um design que perfura fronteiras pré-estabelecidas. Por isso é impossível não querer tocá-los, senti- 
los entre nossos dedos, enfim - amá-los pelo que são no momento em que tocam nossas mãos.

\section{Referências}

Cosac Naify. 18 Fev. 2014. http://www.cosacnaify.com.br/

DAMÁSIO, Antonio (2004). Em Busca de Espinosa: Prazer e Dor na Ciência dos Sentimentos. São Paulo: Companhia das Letras. (2007). O Erro de Descartes: Emoção, Razaão e o Cérebro Humano. São Paulo: Companhia das Letras.

FOER, Jonathan Safran (2010). Tree of Codes. London: Visual Editions.

GUMBRECHT, Hans Ulrich (2010). Produção de Presença: O que o Sentido Não Consegue Transmitir. Rio de Janeiro: Contraponto/Ed. PUC-Rio. (2012). Graciosidade e Estagnação: Ensaios Escolhidos. Rio de Janeiro: PUC-Rio/Contraponto.

(1994). "Rhythm and Meaning." Materialities of Communication.

Org. K. Ludwig Pfeiffer and Hans Ulrich Gumbrecht. Stanford, California: Stanford University Press. 170-182.

LITTAU, Karin (2008). "El Papel de los Afectos en la Crítica Literaria." Teorías de la Lectura: Libros, Cuerpos y Bibliomanía. Buenos Aires: Manantial. 135-162.

KURLAND, Andrea. "Visual Editions - Defenders of Print, Part Three." Entrevista a Anna Gerber e Britt Iversen. Huck Magazine. 10 Maio 2013. Web. 28 Fev. 2014.

http://www.huckmagazine.com/art-and-culture/print/visual-editions/ MELVILLE, Herman (2008). Bartleby, o Escrivão. São Paulo: Cosac Naify.

NORMAN, Donald A. (2008). Design Emocional: Por que Adoramos (ou Detestamos) os Objetos do Dia-a-Dia. Rio de Janeiro: Rocco.

SONTAG, Susan (2001). "Against Interpretation.” [1966] Against Interpretation and Other Essays. New York: Picador. 3-14.

(2001). "One Culture and the New Sensibility." [1966] Against Interpretation and Other Essays. New York: Picador. 293-304.

Visual Editions. 18 Fev. 2014. http://www.visual-editions.com/ 